\title{
Composição fenólica de ligninas dioxano determinadas pela reação oxidativa com o nitrobenzeno(1)
}

\author{
Romualdo Shigueo Fukushima ${ }^{(2)}$ e Ronald Donald Hatfield ${ }^{(3)}$
}

\begin{abstract}
Resumo - A correta quantificação da concentração de lignina em plantas forrageiras, pelo método espectrofotométrico, pressupõe a existência de um padrão de referência. Um padrão de referência deve ter composição fenólica semelhante à da lignina da parede celular. O objetivo deste trabalho foi verificar se ligninas extraídas com solução ácida de dioxano para serem utilizadas como padrão de referência, apresentariam variação na composição fenólica da mesma maneira que a lignina da parede celular. Amostras de parede celular de "bromegrass", milho e trevo-vermelho foram submetidas ao método para extração de ligninas com solução ácida de dioxano. A composição fenólica das ligninas foi analisada mediante oxidação alcalina pelo nitrobenzeno com posterior separação dos componentes monoméricos via HPLC. As ligninas extraídas confirmaram a existência de variação na composição fenólica da mesma maneira às ligninas intactas presentes na parede celular e de substancial presença de ácidos cinâmicos nas ligninas de gramíneas. No que diz respeito à composição fenólica, ligninas extraídas com solução ácida de dioxano podem ser consideradas potenciais padrões de referência paras as análises espectrofotométricas.
\end{abstract}

Termos para indexação: parede celular, planta forrageira, ácido cinâmico, ácido ferúlico.

\section{Phenolic composition of dioxane lignins as determined by nitrobenzene oxidative reaction}

\begin{abstract}
The correct quantification of lignin concentration in forages through the spectrophotometric method presumes the existence of a reference standard. This standard must have a phenolic composition similar to the cell wall lignin. The objective of this work was to verify if the lignins extracted with acidic dioxane solution to be used as reference standard would present the same variation in the phenolic composition as it occurs in the cell wall lignin. Bromegrass, corn and red clover cell wall samples were submitted to the method for extraction of lignins with an acidic dioxane solution. The phenolic composition of the extracted lignins was analyzed by alkaline nitrobenzene oxidation followed by HPLC separation. Extracted lignins confirmed that they have phenolic composition variation the same way as do intact lignins present in the cell wall and that grass lignins showed substantial presence of cinnamic acids. Concerning to phenolic composition lignins extracted by acidic dioxane may potentially be used as reference standards in the spectrophotometric analysis.
\end{abstract}

Index terms: cell walls, forage crops, cinnamic acid, ferulic acid.

\section{Introdução}

A maximização na produção de leite e de carne por animais ruminantes depende, principalmente, de

\footnotetext{
(1) Aceito para publicação em 10 de dezembro de 2002.

(2)Universidade de São Paulo, Fac. de Medicina Veterinária e Zootecnia, Av. Duque de Caxias Norte, 225, CEP 13630-000 Pirassununga, SP. E-mail: rsfukush@usp.br

${ }^{(3)}$ United States Department of Agriculture, Agricultural Research Service, U.S. Dairy Forage Research Center, 1925 Linden Drive West, Madison, Wisconsin 53706 - USA. E-mail: rdhatfie@facstaff.wisc.edu
}

adequado aporte de nutrientes e energia. Para que isso ocorra, além de atender a vários outros pré-requisitos, é de fundamental importância a máxima utilização do potencial nutritivo dos alimentos concentrados e volumosos. Quanto aos alimentos volumosos, o principal obstáculo à digestão microbiana dos carboidratos da parede celular é a lignina.

A lignina é um polímero formado por três álcoois, p-coumaril, coniferil e sinapil, que se interligam numa malha complexa, resistente à hidrólise ácida e alcalina e a vários complexos enzimáticos, inclusive as enzimas microbianas e tissulares do trato 
gastrintestinal dos animais superiores. À medida que as plantas forrageiras amadurecem, maior é a concentração da lignina, bem como maior é seu efeito deletério sobre a utilização da parede celular (Soest, 1994).

Verifica-se, pois, a relevância da correta quantificação da concentração de lignina em plantas forrageiras. No entanto, os métodos analíticos atualmente em uso não têm se mostrado satisfatórios (Hatfield et al., 1994; Fukushima \& Dehority, 2000). Um método espectrofotométrico foi empregado para determinar o teor de lignina em plantas forrageiras (Morrison, 1972), mas todo método espectrofotométrico pressupõe a existência de um padrão de referência com o qual as leituras de densidade óptica das amostras são comparadas (Fengel \& Wegener, 1984). Dada à inexistência de um padrão adequado, Morrison (1972) elaborou equações de regressão com base nos valores de lignina ácida das mesmas amostras. Como o método de determinação da lignina ácida apresenta sérios problemas analíticos, questiona-se a validade dessas equações de regressão.

Recentemente, reportou-se a extração de ligninas com solução ácida de dioxano objetivando empregar essas ligninas como padrões de referência (Fukushima \& Hatfield, 2001). Ignora-se se a lignina extraída com solução ácida de dioxano apresentaria variação na composição fenólica da mesma maneira que a lignina presente na parede celular, cuja composição fenólica varia de acordo com a espécie e tecido da planta. Este aspecto é mais relevante ainda quando são analisadas ligninas de gramíneas, pois estas apresentam substancial participação de ácidos cinâmicos em suas estruturas.

Diferenças significativas nas composições fenólicas entre a lignina presente na parede celular e a extraída com solução ácida de dioxano poderiam comprometer o emprego desta como padrão de referência.

O objetivo deste trabalho foi analisar a composição monomérica em fenóis de algumas ligninas extraídas com solução ácida de dioxano e compará-la com a composição fenólica da lignina da parede celular.

\section{Material e Métodos}

\section{Ligninas}

$\mathrm{Na}$ extração das ligninas, foram usados caules de "bromegrass" (Bromus inermis L.), do milho (Zea mays L.) e do trevo-vermelho (Trifolium pratense L.), e tronco do pinheiro (Pinus taeda L.). "Bromegrass" foi colhido quando da emergência da panícula e início da abertura das primeiras flores; as plantas de milho foram colhidas quando os grãos se apresentavam no estádio farináceo; cortes do trevo-vermelho foram realizados no início do florescimento (cerca de $20 \%$ de flores abertas); a amostra de pinheiro foi proveniente de madeira madura.

O "bromegrass" e o milho foram cultivados sob condições controladas de temperatura e regime luminoso, em estufa pertencente ao United States Department of Agriculture - Dairy Forage Research Center (USDA DFRC), Madison, Wisconsin, USA. O trevo-vermelho foi colhido de uma área experimental, localizada na University of Wisconsin Experimental Farm, Arlington, Wisconsin. Amostras de pinheiro foram doações do USDA - Forest Products Laboratory (S. Ralph and L. Landucci); embora o pinheiro não seja uma matéria-prima alimentar para os animais ruminantes, foi utilizado por ter lignina $100 \%$ formada de núcleos guaiacílicos, que após reação com o nitrobenzeno dá origem a poucos produtos de oxidação, a vanilina e o ácido vanílico.

Os materiais vegetais colhidos, exceto o pinheiro, que veio sob a forma de serragem, foram secados em estufa a $60^{\circ} \mathrm{C}$ com ventilação forçada de ar e a seguir moídos em moinho laboratorial (Willey) com peneira de $0,5 \mathrm{~mm}$. A parede celular desses materiais foi obtida por refluxo seqüencial com água destilada, etanol, clorofórmio e acetona, em aparelho de Soxhlet. Após serem secadas, as amostras da parede celular foram armazenadas em frascos de vidro. Para a obtenção da lignina, as amostras de parede celular foram submetidas à extração com solução ácida de dioxano (LDiox), segundo Fukushima \& Hatfield (2001).

\section{Oxidação com nitrobenzeno}

Oxidação da lignina com nitrobenzeno em meio alcalino tem sido importante método analítico para determinar em termos qualitativos e quantitativos os blocos constitutivos das ligninas desde o final da década de 30 (Fengel \& Wegener, 1984). O procedimento foi a reação original descrita por Freudenberg et al. (1940) com modificações sugeridas por Iiyama \& Lam (1990). No presente trabalho o método foi ligeiramente alterado.

Aproximadamente $10 \mathrm{mg}$ de LDiox foram pesadas em tubos de aço inoxidável; $4,0 \mathrm{~mL}$ de solução $2 \mathrm{M}$ de $\mathrm{NaOH}$ e $0,25 \mathrm{~mL}$ de nitrobenzeno foram pipetados em cada tubo e estes hermeticamente fechados. Os tubos foram mantidos a $170^{\circ} \mathrm{C}$ por duas horas e meia em banho de areia. A seguir, o conteúdo do tubo foi cuidadosamente transfe- 
rido para um tubo de cultura de $25 \mathrm{~mL}$ e lavado com água (três vezes $5,0 \mathrm{~mL}$ ). Isovanilina $(50 \mu \mathrm{L}$ de uma solução $10 \mathrm{mg} / \mathrm{mL}$ em etanol) foi adicionada para servir como padrão interno. Essa mistura foi extraída duas vezes com $5,0 \mathrm{~mL}$ de clorofórmio $\left(\mathrm{CHCl}_{3}\right)$ e a fase orgânica descartada; a fração aquosa remanescente foi acidificada com solução concentrada de $\mathrm{HCl}(10 \mathrm{~N})$ para $\mathrm{pH}$ inferior a 2,5 e lentamente eluída por meio de uma coluna de extração sólida $\mathrm{C}_{18}$ fase reversa (Envir-18, Supelco Inc.). Essa coluna havia sido condicionada previamente com a seguinte seqüência de solventes (2,0 mL de cada): $\mathrm{dH}_{2} \mathrm{O}$ (água destilada e deionizada), metanol (MeOH), $\mathrm{MeOH}: \mathrm{CHCl}_{3}$ (1:1), $\mathrm{CHCl}_{3}, \mathrm{MeOH}: \mathrm{CHCl}_{3}(1: 1), \mathrm{MeOH}, \mathrm{dH}_{2} \mathrm{O}$ e solução $2 \mathrm{~N}$ de $\mathrm{NaOH}$ (pH ajustado para menos de 2,5 com solução $10 \mathrm{~N} \mathrm{de} \mathrm{HCl}$ ). Após passagem da amostra, a coluna foi lavada com $\mathrm{dH}_{2} \mathrm{O}$ (pH ajustado para menos de 2,5 com ácido trifluoroacético); todas essas soluções "limpadoras" foram adequadamente descartadas.

Os compostos fenólicos (aldeídos, cetonas e ácidos) retidos na coluna foram eluídos com metanol e tetraidrofurano (THF) (duas vezes com 2,0 mL de cada solvente) e colhidos em um tubo cônico de $15 \mathrm{~mL}$. $\mathrm{O}$ volume combinado desses dois solventes foi reduzido para aproximadamente um terço do volume original, sob um fino jato de ar comprimido, filtrado e seco. Uma subamostra $(1,0 \mathrm{~mL})$ foi colocada em um receptáculo de $8,0 \mathrm{~mL}$ e totalmente evaporada, dissolvida em $10 \mu \mathrm{L}$ de THF e $40 \mu \mathrm{L}$ do agente derivatizante N,O-bis (trimetilsilil) trifluoroacetimida e aquecida a $60^{\circ} \mathrm{C}$ por 20 minutos.

Dessa subamostra, $1 \mu \mathrm{L}$ foi injetado em um aparelho de cromatografia gasosa, equipado com detector de ionização de chama (HP 6890 Agilent, Hewlett Packard Co., EUA) e os compostos fenólicos separados em uma coluna capilar (DB-1 ${ }^{\mathrm{TM}} 25 \mathrm{~m} \mathrm{X} \mathrm{0,2} \mathrm{mm,} \mathrm{J \& W} \mathrm{Scientific,}$ Inc.), mediante o seguinte gradiente de temperatura: temperatura inicial do forno de $160^{\circ} \mathrm{C}$, durante $5 \mathrm{~min}$; elevação da temperatura até $200^{\circ} \mathrm{C} \mathrm{a} 4^{\circ} \mathrm{C} / \mathrm{min}$; nova elevação até $240^{\circ} \mathrm{C}$ a $10^{\circ} \mathrm{C} / \mathrm{min}$, mantendo-se nesse patamar por $5 \mathrm{~min}$; e temperatura final de $300^{\circ} \mathrm{C}$, mantida por $5 \mathrm{~min}$, após rampa a $15^{\circ} \mathrm{C} / \mathrm{min}$, perfazendo um tempo total de separação de 33 minutos. Os seguintes fenóis foram utilizados como padrões de referência $(100 \mu \mathrm{g} / \mathrm{mL}$ cada): p-hidroxibenzaldeído, vanilina, isovanilina (padrão interno), acetovanilona, siringaldeído, 3,5-dimetoxi-4-hidroxiacetofenona, ácido vanílico, ácido siríngico, ácido p-coumárico e ácido ferúlico. Esses padrões foram submetidos às mesmas condições de tratamento que as amostras de lignina. O leque no número de substâncias-padrão foi amplo pois pretendeu-se dar cobertura ao maior número possível de compostos fenólicos que a oxidação alcalina pelo nitrobenzeno viesse a revelar. Tipicamente, a oxidação dos núcleos guaiacílicos resulta em vanilina, ácido vanílico e ácido ferúlico, enquanto a oxidação das unidades siringílicas origina siringaldeído e o ácido siríngico; e finalmente, a reação do nitrobenzeno com os núcleos aromáticos do tipo $\mathrm{p}$-coumarílico produz o p-hidroxibenzaldeído e o ácido p-coumárico.

Todas as análises foram realizadas em triplicatas, com três amostras diferentes de cada planta.

\section{Espectroscopia ultravioleta}

Saponificação em meio alcalino remove substâncias esterificadas à molécula de lignina, tais como os acetatos, p-coumaratos e ferulatos (Morrison \& Stewart, 1995). As amostras de lignina foram tratadas com solução $2 \mathrm{M}$ de $\mathrm{NaOH}$, por 24 horas, à temperatura ambiente. Seguindo-se a acidificação da solução $(\mathrm{HCl} 6 \mathrm{~N})$ e conseqüente floculação da lignina, esta foi separada por centrifugação $(9.000 \mathrm{~g}, 15 \mathrm{~min})$ e a porção líquida submetida a uma varredura ultravioleta, no intervalo de 250 a $350 \mathrm{~nm}$, em um espectrofotômetro Beckman, modelo DU-50.

\section{Resultados e Discussão}

Da mesma maneira que em várias outras técnicas analíticas para quantificar lignina, a oxidação da lignina pelo nitrobenzeno também não é completa. Por causa da heterogeneidade com que as moléculas de lignina se apresentam na natureza (Billa et al., 1996), não foram empregados fatores de correção objetivando estimar a concentração total de lignina. A LDiox do milho mostrou os seguintes monômeros fenólicos (em parênteses, o tempo de retenção, em minutos): p-hidroxibenzaldeído $(5,4)$, vanilina $(8,3)$, padrão interno isovanilina $(8,8)$, siringaldeído $(12,4)$, ácido siríngico $(17,4)$, ácido p-coumárico $(18,1)$ e ácido ferúlico $(20,5)$. O pico que se projeta aos 20 min é um produto de degradação do nitrobenzeno, denominado difenilazóxido (Chan \& Allan, 1971). Os produtos de oxidação da lignina do trevo-vermelho foram: vanilina $(8,3)$, isovanilina $(8,8)$, siringaldeído $(12,4)$, ácido siríngico $(17,4)$ e ácido p-coumárico $(18,1)$. Como seria de se esperar, os tempos de retenção para os monômeros foram exatamente os mesmos nas duas forrageiras.O p-hidroxibenzaldeído e o ácido ferúlico aparecem na lignina do milho, mas não na do trevo-vermelho, enquanto o ácido p-coumárico, abundante no milho, aparece em quantidades traço no trevo (Tabela 1). 
Com a exceção do pinheiro, cuja lignina é exclusivamente do tipo guaiacílico, nas demais espécies a lignina é constituída da mistura de núcleos siringílico e guaiacílico, o que resulta em predominância de vanilina e siringaldeído como os principais produtos de oxidação (Tabela 1). Como reportado por Harris \& Hartley (1976) e Morrison \& Stewart (1995), os derivados cinâmicos foram detectados em apreciáveis teores nas gramíneas. No caso do milho, uma gramínea $\mathrm{C}_{4}$, a soma desses derivados foi igual à soma dos núcleos siringílicos (siringaldeído e ácido siríngico), enquanto no "bromegrass" (uma $\mathrm{C}_{3}$ ) houve detecção dos ácidos p-coumárico e ferúlico, mas em menor quantidade que no milho. Esses compostos estão presentes nas leguminosas somente em quantidades ínfimas e esta diferença pode ser a razão pela qual distintas equações de regressão devem ser empregadas para gramíneas e leguminosas para transformar valores de absorbância em teores de lignina (Morrison, 1972; Morrison \& Stewart, 1995). Os ácidos p-coumárico e ferúlico estão presentes em diferentes ligações e arranjos químicos na parede celular e absorvem fortemente em $280 \mathrm{~nm}$, o mesmo comprimento de onda usado para a determinação da lignina. Tal fato também foi constatado por Fukushima \& Hatfield (2001), em que estes compostos foram os prováveis responsáveis por ligeira elevação no espectrograma oriundo do milho em relação às outras plantas estudadas. O caule de milho apresentou substancial presença de ácido p-coumárico, que, segundo Ralph et al. (1994), se apresenta esterificado ao carbono $\gamma$ da unidade fenilpropanóide. A detecção de ácidos cinâmicos entre os produtos de oxidação pelo nitrobenzeno em gramíneas já havia sido observada
(Lam et al., 1990; Billa et al., 1996). Ácidos p-coumárico e ferúlico podem ser oxidados para p-hidroxibenzaldeído e vanilina, respectivamente (Higuchi et al., 1967), e ser considerados parte da estrutura da lignina. Entretanto, Morrison \& Stewart (1995) propuseram que todos os ácidos cinâmicos ligados à molécula de lignina através de ligações covalentes do tipo éter sejam considerados parte integrante da lignina e, por sua vez, aqueles ligados através de ligações éster deveriam ser excluídos. A questão é se deve-se considerar esses ácidos como parte integrante da estrutura da molécula de lignina ou como entidades químicas à parte.

O tratamento das ligninas isoladas com solução alcalina facilmente removeu os ácidos cinâmicos, como pode ser constatado no espectro das varreduras das soluções alcalinas apresentado na Figura 1. As gramíneas, particularmente o milho, apresentaram forte absorção ultravioleta na região dos $280 \mathrm{~nm}$. Essas curvas são características dos ácidos p-coumárico e ferúlico (Iiyama \& Wallis, 1990), concordando com os resultados mostrados pela técnica da oxidação com o nitrobenzeno. Não seria de se esperar picos semelhantes aos das gramíneas nas soluções alcalinas do trevo-vermelho e pinheiro. De fato, apenas ínfima concentração de fenóis estava presente. Reforça esta afirmação o fato de que não foi feita qualquer diluição das soluções alcalinas do trevo e pinheiro, enquanto com o milho e o "bromegrass" diluições da ordem de 10 e 4 vezes, respectivamente, foram necessárias. Embora Morrison \& Stewart (1995) tenham sugerido a possibilidade de quantificar esses ácidos por intermédio de cromatografia, líquida ou gasosa, nenhuma tentativa de quantificar esses ácidos foi feita, uma

Tabela 1. Produtos de oxidação das ligninas dioxano pelo nitrobenzeno (mmoles $\mathrm{g}^{-1}$ de lignina) ${ }^{(1)}$.

\begin{tabular}{|c|c|c|c|c|c|c|c|c|}
\hline Amostra & PHBA & Van & Sir & Avan & Asir & pCA & FA & Total \\
\hline & & & & & noles & & & \\
\hline Milho & 0,14 & 0,35 & 0,61 & 0,02 & 0,12 & 0,60 & 0,12 & 1,96 \\
\hline "Bromegrass" & 0,05 & 0,69 & 0,58 & 0,02 & 0,05 & 0,20 & 0,05 & 1,64 \\
\hline Trevo-vermelho & 0,01 & 0,67 & 0,61 & 0,09 & 0,14 & 0,00 & 0,02 & 1,54 \\
\hline Pinheiro & 0,07 & 1,03 & 0,00 & 0,23 & 0,00 & 0,00 & 0,00 & 1,33 \\
\hline Média & 0,07 & 0,68 & 0,45 & 0,09 & 0,08 & 0,20 & 0,05 & 1,62 \\
\hline Erro-padrão da média & 0,03 & 0,14 & 0,01 & 0,05 & 0,03 & 0,14 & 0,03 & 0,14 \\
\hline
\end{tabular}

${ }^{(1)}$ Valores são médias de duas observações; PHBA: p-hidroxibenzaldeído; Van: vanilina; Sir: siringaldeído; Avan: ácido vanílico; Asir: ácido siríngico; pCA: ácido p-coumárico; FA: ácido ferúlico. 


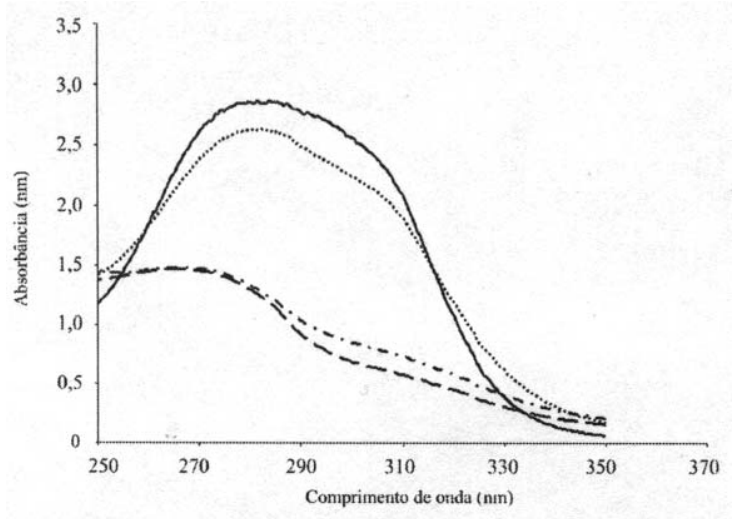

Figura 1. Espectro da varredura entre 250 e $350 \mathrm{~nm}$ das soluções alcalinas empregadas para tratar as ligninas extraídas do milho (_ $)$, "bromegrass" (.........), trevo-vermelho (_ - - ) e pinheiro (_ _ ).

vez que o principal escopo da saponificação foi apenas o de confirmar os achados resultantes da oxidação pelo nitrobenzeno.

\section{Conclusões}

1. As ligninas extraídas com solução ácida de dioxano apresentam variação na composição fenólica da mesma maneira que se tem reportado em relação às ligninas intactas presentes na parede celular.

2. As ligninas extraídas de gramíneas, particularmente do milho, apresentam substancial presença dos derivados de ácidos cinâmicos.

3. As ligninas extraídas com solução ácida de dioxano podem ser consideradas potenciais padrões de referência para as análises espectrofotométricas.

\section{Agradecimentos}

À Fundação de Amparo à Pesquisa do Estado de São Paulo, pelo auxílio à pesquisa no exterior.

\section{Referências}

BILlA, E.; TOLLIER, M. T.; MONTIES, B. Characterization of the monomeric composition of in situ wheat straw lignins by alkaline nitrobenzene oxidation: effect of temperature and reaction time. Journal of the Science of Food and Agriculture, Chichester, v. 72, p. 250-256, 1996.

CHANG, H. M.; ALLAN, G. G. Oxidation. In: SARKANEN, K. V.; LUDWIG, C. H. (Ed.). Lignins: occurrence, formation, structure and reactions. New York: J. Wiley, 1971. p. 433-485.

FENGEL, D.; WEGENER, G. Wood: chemistry, ultrastructure, reactions. Berlin: W. de Gruyter, 1984. p. 132-191.

FREUDENBERG, K.; LAUTSCH, W.; ENGLER, K. Die Bildung von Vanillin aus Fichtenlignin. Berichte der Deutschen Chemischen Gesellschaft, Heidelberg, v. 73, p. 167-173, 1940.

FUKUSHIMA, R. S.; DEHORITY, B. A. Feasibility of using lignin isolated from forages by solubilization in acetyl bromide as a standard for lignin analysis. Journal of Animal Science, Savoy, v. 78, p. 3135-3143, 2000.

FUKUSHIMA, R. S.; HATFIELD, R. D. Extraction and isolation of lignin and its utilization as a standard to determine lignin concentration through a spectrophotometric method. Journal of Agricultural and Food Chemistry, Washington, v. 49, p. 3133-3139, 2001.

HARRIS, P. J.; HARTLEY, R. D. Detection of bound ferulic acid in cell walls of the Gramineae by ultraviolet fluorescence microscopy. Nature, London, v. 259, p. 508510, 1976.

HATFIELD, R. D.; JUNG, H. G.; RALPH, J.; BUXTON, D. R.; WEIMER, P. J. A comparison of the insoluble residues produced by the Klason lignin and acid detergent lignin procedures. Journal of the Science of Food and Agriculture, Chichester, v. 65, p. 51-58, 1994.

HIGUCHI, T.; ITO, Y.; KAWAMURA, I. Chemical properties of milled wood lignins of grasses. Phytochemistry, Long Island, v. 6, p. 1551-1556, 1967.

IIYAMA, K.; LAM, T. B. T. Lignin in wheat internodes part 1: the reactivities of lignin units during alkaline nitrobenzene oxidation. Journal of the Science of Food and Agriculture, Chichester, v. 51, p. 481-491, 1990.

IIYAMA, K.; WALLIS, A. F. A. Determination of lignin in herbaceous plants by an improved acetyl bromide procedure. Journal of the Science of Food and Agriculture, Chichester, v. 51, p. 145-161, 1990. 
LAM, T. B. T.; IIYAMA, K.; STONE, B. A. Lignin in wheat internodes - part 2: alkaline nitrobenzene oxidation by wheat straw lignin and its fractions. Journal of the Science of Food and Agriculture, Chichester, v. 51, p. 493-506, 1990.

MORRISON, I. M. Improvements in the acetyl bromide technique to determine lignin and digestibility and its application to legumes. Journal of the Science of Food and Agriculture, Chichester, v. 23, p. 1463-1469, 1972.

MORRISON, I. M.; STEWART, D. Determination of lignin in the presence of ester-bound substituted cinnamic acids by a modified acetyl bromide procedure. Journal of the Science of Food and Agriculture, Chichester, v. 69, p. 151-157, 1995.

RALPH, J.; HATFIELD, R. D.; QUIDEAU, S.; HELM, R. F.; GRABBER, J. H.; JUNG, H. G. Pathway of $p$-coumaric acid incorporation into maize lignin as revealed by NMR. Journal of the American Chemical Society, Washington, v. 116, p. 9448-9456, 1994.

SOEST, P. J. van. Nutritional ecology of the ruminant. Ithaca: Comstock Publishing Associates/Cornell University Press, 1994. 476 p. 